\title{
Molecular phylogeny and divergence of photosynthetic pathways of Korean Cypereae (Cyperaceae)
}

\author{
Jongduk Jung*, Youngil Ryu and Hong-Keun Choi ${ }^{1}$ \\ Northeastern Asia Biodiversity Institute, Seoul 05677, Korea \\ ${ }^{1}$ Department of Biological Science, College of Natural Sciences, Ajou University, Suwon 16499, Korea \\ (Received 19 September 2016; Revised 29 September 2016; Accepted 29 September 2016)
}

\section{한국산 방동사니족(사초과) 식물의 분자계통과 광합성경로의 분화}

\author{
정종덕* · 류영일 · 최홍근 ${ }^{1}$ \\ 동북아생물다양성연구소, ${ }^{1}$ 아주대학교 자연과학대학 생명과학과
}

\begin{abstract}
Multiple changes of the photosynthesis pathway are independent evolutionary events occurring in the phylogeny of flowering plants, and such changes have occurred more than five times in Cyperaceae. In the tribe Cypereae, the $\mathrm{C} 4$ photosynthetic pathway appeared only once and is regarded as a synapomorphy of the $\mathrm{C} 4$ plants within this tribe. The morphological delimitation of genera within Cypereae does not correspond to their molecular phylogenetic relationships. In this study, the molecular phylogeny was compared with the photosynthetic pathways of Korean Cypereae (18 species of Cyperus, 1 species of Kyllinga, and 1 species of Lipocarpha). The photosynthetic pathways were determined by observing the leaf anatomy. The phylogenetic analysis was performed using three DNA regions (nrITS, $r b c L$, and $t r n L-F)$. According to the position of the photosynthetic tissue, 4 species $(C$. difformis, C. flaccidus, C. haspan, and C. tenuispica) and 16 species (14 Cyperus species, K. brevifolia var. leiolepis, and L. microcephala) were confirmed as $\mathrm{C} 3$ and $\mathrm{C} 4$ plants, respectively. Tribe Cypereae was divided into the CYPERUS and FICINIA clades, and all species of Korean Cypereae plants belonged to the CYPERUS clade in the phylogenetic analysis. Within the CYPERUS clade, C4 plants were monophyletic but their phylogenetic relationships were unclear. The genera Kyllinga and Lipocarpha were not supported as an independent genus in either case because they were nested by the Cyperus species in the molecular phylogenetic trees in the present and in previous studies. To determine the classification within the CYPERUS clade, a detailed morphological study and a molecular phylogenetic analysis at a high resolution will be necessary.
\end{abstract}

Keywords: Cyperus, Kyllinga, Lipocarpha, photosynthesis pathway, C4 plant, Kranz anatomy

적 요: 광합성 경로의 전환은 현화식물의 계통에서 여러 번에 걸쳐서 독립적으로 일어난 진화적 사건으 로서 사초과에서는 다섯 번 이상 발생한 것으로 추정되고 있다. 방동사니족에서 나타난 $\mathrm{C} 4$ 광합성 경로로 의 전환은 한 번 발생하였으며 이는 방동사니족 내 $\mathrm{C} 4$ 식물의 공유파생형질로 여겨진다. 방동사니족에 포 함된 속들의 형태학적 한계는 분자계통학적 유연관계와 일치하지 않으며, 특히 다계통군으로 여겨지는 방동사니속의 한계는 계통분류학적으로도 논란이 되고 있다. 본 연구에서는 한국산 방동사니족 식물의 광합성 경로와 분자계통을 비교하고자 하였다. 해부학적 관찰을 통해 우리나라 방동사니족 식물 20 종(방 동사니속 18 종, 파대가리속 1종, 세대가리속 1종)의 광합성 경로를 확인하였다. 또한 $\mathrm{nrITS}, r b c L, t r n L-F$ 의 염기서열에 근거하여 각 분류군의 분자계통학적 위치를 파악하고자 하였으며, 분류군 전체의 계통을 파

*Author for correspondence: jungjongduk@gmail.com 
악하기 위하여 선행연구 결과와 함께 분석하였다. 엽록체가 밀집된 광합성 조직의 위치에 따라 우리나라 방동사니속 식물 중 병아리방동사니와 우산방동사니, 모기방동사니, 알방동사니의 네 종은 $\mathrm{C} 3$ 식물로 확 인되었고, 나머지 14종의 방동사니속 식물, 파대가리, 그리고 세대가리는 C4 식물로 결정되었다. 또한 분 자계통학적 분석에서 방동사니족은 CYPERUS 분계군과 FICINIA 분계군으로 구분되었으며, 우리나라 방 동사니족 식물은 모두 CYPERUS 분계군에 속하였다. CYPERUS 분계군내에서 C4 식물들은 단계통군을 형성하였지만 각 분류군 간의 유연관계는 명확하게 나타나지 않았다. 분자계통수에서 세대가리속과 파대 가리속은 $\mathrm{C4}$ 식물인 방동사니속 식물들과 함께 단일 분계군을 형성함으로서 각각 독립된 속으로서 지지 되지 않는다. 이는 기존의 연구결과와 일치하며, CYPERUS 분계군에 속한 속들의 계통분류체계를 명확하 게 하기 위해서는 면밀한 형태학적 연구와 더불어 높은 해상력을 갖춘 분자계통학적 연구가 이루어져야 할 것이다.

주요어: 방동사니속, 파대가리속, 세대가리속, 광합성 경로, $\mathrm{C} 4$ 식물, 크란츠 구조

사초과(Cyperaceae Juss.) 식물은 극지를 제외한 전세계 에 5,400 여 종이 분포하는 것으로 알려져 있으며, 이 중 온 대와 열대에 분포하는 1,000 여 종이 방동사니족(Cypereae) 에 속한다(Goetghebeur, 1998; Govaerts et al., 2007). 린네는 방동사니속(Cyperus L.) 식물의 소수에 인편이 두 줄로 배 열하는 점을 들어서 인편이 나선형으로 돌려 나는 고랭이 속(Scirpus L.)과 구분하였다(Linnaeus, 1753, 1754). 그러나 속의 구분에 사용된 인편의 배열형태는 현대적인 사초과 분류체계에서 방동사니족(Cypereae)과 고랭이족(Scirpeae) 의 보편적인 특징으로 여겨지고 있으며, 예외적인 경우가 많다(Bruhl, 1995; Goetghebeur, 1998). 최근 분자계통학적 연구에 의해서 밝혀진 사초과 식물에 대한 구분에 따르면, 방동사니족은 네 개의 족으로 구성된 FAEC 분계군(검정방 동사니족[Fuireneae]+Abildgaardieae+바늘골족[Eleocharideae] + 방동사니족)에 속하며, 방동사니족은 두 개의 분계군 (CYPERUS 분계군과 FICINIA 분계군)으로 뚜렷이 나뉜 다(Muasya et al., 2009a; Jung and Choi, 2013). 방동사니족은 전세계적으로 20 개 속을 포함하며, 그 중 8 개 속(약 150 종) 은 FICINIA 분계군에 속하고 나머지 12개 속(약850종)은 CYPERUS 분계군에 포함된다(Muasya et al., 2009a; Jung and Choi, 2013).

CYPERUS 분계군에 속하는 우리나라 식물은 3 개 속 (방동사니속, 파대가리속[Kyllinga Rottb.], 세대가리속 [Lipocarpha R. Br.])이다. 파대가리속과 세대가리속의 식 물은 하나의 소수에 들어있는 꽃의 수가 1-수 개로 매우 적어서 꽃의 수가 많은 방동사니속과 형태적으로 구분된 다(Goetghebeur, 1998). 세대가리속 식물은 소수의 포가 꽃 을 끼고 있는 인편보다 훨씬 크고, 반대로 파대가리속은 인편의 크기가 큰 것이 특징이다(Ohwi, 1944; Goetghebeur, 1998). 방동사니속에 대한 형태학적 속의 한계는 학자들 의 견해에 따라 다양하다. 즉, 방동사니속 식물은 소수에 꽃을 끼고 있는 인편이 두 줄로 배열하고, 화피편(또는 화 피강모)이 없는 특징을 가지고 있는 것에 근거하여 속의 한계가 넓게 적용된 바(Cyperus s.1.)가 있다(Ohwi, 1944; Tucker et al., 2002). 이와 달리 주두열편의 수와 열매(수과)
의 방향성에 따라 Pycreus P. Beauv.속과 좁은 의미의 방동 사니속(Cyperus s. str.)으로 나누어 보는 견해도 있다 (Goetghebeur, 1998; Muasya et al., 2001). 이보다 더 세분된 속 (Cyperus s. str., Pycreus, Juncellus C. B. Clarke, Mariscus Vahl, Torulinium C. B. Clarke 등)으로 다룬 경우도 있지만 (Clarke, 1908), Pycreus 속만을 독립적인 속으로 취급하고 나머지는 방동사니속으로 통합하거나(Goetghebeur, 1998), 모두 광의의 방동사니속(Cyperus s.l.)의 아속이나 절로서 다루는 것이 보편적이다(Ohwi, 1944; Tucker et al., 2002). 방동사니족에 속하는 속의 형태학적 특징은 비교적 뚜렷 한 것으로 여겨져 왔으나 분자계통학적 유연관계와 부합 하지 않아 혼란이 있다(Goetghebeur, 1998; Muasya et al., 2001, 2009b; Jung and Choi, 2013). 최근에는 분자계통학적 해석에 근거하여 방동사니속과 근연속 대부분의 종들을 하나의 속으로 다루고자 하는 의견도 제시되고 있다 (Larridon et al., 2013; Bauters et al., 2014).

$\mathrm{C} 4$ 광합성 경로는 수렴진화의 대표적인 예로서, 현화식 물의 18 개과에서 발견되며 45 회 이상 일어난 진화적 사건 으로 알려져 있으며, 사초과에서는 다섯 번 이상의 변화 가 있었던 것으로 추정된다(Sage, 2004; Besnard et al. 2009). 단자엽식물에서는 대표적인 경제작물들이 포함된 벼과(Poaceae)뿐만 아니라, 사초과의 여러 속(골풀아재비 속[Rhynchospora Vahl], 하늘지기속[Fimbristylis Vahl], 모기 골속[Bulbostylis Kunth], 바늘골속[Eleocharis R. Br.], 방동 사니속 등)에 $\mathrm{C} 4$ 식물이 포함되어 있으며, 방동사니속에 서는 C4 식물과 C3 식물이 함께 나타난다 (Sage, 2004; Besnard et al., 2009). 분자계통학적 분석을 통해 CYPERUS 분계군 내에서 $\mathrm{C} 3$ 식물이 $\mathrm{C} 4$ 식물로 전환된 진화적 단계 가 보고되었고 계통관계를 파악하는 데 이용되었다 (Muasya et al., 2002; Larridon, 2011). C4 광합성 경로를 가 진 식물은 $\mathrm{C} 3$ 식물에 비해 덥고 건조한 지역에서 유리한 것으로 알려져 있다(Tieszen et al., 1979). C4 식물은 엽록체 가 밀집된 광합성 조직(엽육세포와 유관속초세포)이 유 관속을 고리형태로 둘러싼 해부학적 특징(Kranz anatomy) 으로 광합성 조직(엽육세포)이 표피 아래에 넓게 분포하 
는 C3 식물과 쉽게 구별이 가능하다(Dengler and Nelson, 1999; Lee, 2004). 다만 사초과 C4 식물의 광합성 조직 중에 서 유관속초와 유사한 형태의 조직은 전형적인 $\mathrm{C} 4$ 식물의 유관속초와는 발생학적인 유래가 다른 것으로 알려져 있 다(Soros and Bruhl, 2000).

우리나라에는 방동사니족 식물 21종(방동사니속 19종, 파대가리속 1종, 세대가리속 1종)이 분포하는 것으로 보 고되었다(Ohwi, 1944; Chung, 1957; Lee, 1996; Lee, 2003; Lee, 2006; Oh, 2007) (Table 1). 다만, 껄끔방동사니(C. diaphanus Schrad.)의 국내 분포지는 잘 알려져 있지 않다 (Ohwi, 1965; Lee, 1996). 또한 일부 국명이 혼용되어 왔는 데 그 예로서 우산방동사니는 C. flavidus Retz.와 C. tenuispica Steud.의 국명으로 사용되었고, 방동사니는 $C$. amuricus Maxim.와 C. microiria Steud.의 국명으로 사용되 었다(Chung, 1957; Lee, 2006; Oh, 2007) (Table 1). 우리나라 의 방동사니족 식물에 대한 연구로는 방동사니속 18 종에 대하여 화서와 꽃, 열매 등 생식기관의 형태학적 특징이 다루어진 바가 있다(Oh and Lee, 1999). 또한 동일한 분류

Table 1. Species list of Korean Cyperus and the related genera reported in representative floral literatures.

\begin{tabular}{|c|c|c|c|c|c|c|c|}
\hline Taxon & $\begin{array}{l}\text { Ohwi } \\
(1944, \\
1965)\end{array}$ & $\begin{array}{l}\text { Chung } \\
(1957)(\end{array}$ & $\begin{array}{l}\text { Lee } \\
(1996)\end{array}$ & $\begin{array}{l}\text { Lee } \\
(2003)\end{array}$ & $\begin{array}{l}\text { Lee } \\
(2006)\end{array}$ & $\begin{array}{c}\mathrm{Oh} \\
(2007)\end{array}$ & Korean name (Reference) \\
\hline $\begin{array}{l}\text { Genus Cyperus L. } \\
\text { Subgenus Pycreus }\end{array}$ & & & & & & & \\
\hline C. diaphanus Schrad. & 0 & - & 0 & - & - & - & Kkeol-kkeum-bang-dong-sa-ni (L1) \\
\hline $\begin{array}{l}\text { C. flavidus Retz. } \\
\text { (= C. globosus All.) } \\
\text { (= C. nilagiricus Hochst. ex Steud.) }\end{array}$ & - & - & - & - & - & - & $\begin{array}{l}\text { U-san-bang-dong-san-i (C), Non-ttuk-bang-dong-sa-ni } \\
\text { (L1), Deu-reong-bang-dong-sa-ni (L2, L3, O) }\end{array}$ \\
\hline C. polystachyos Rottb. & ○ & - & - & 0 & 0 & $\bullet$ & $\begin{array}{l}\text { Bam-song-i-bang-dong-sa-ni (L1), Gaet-bang-dong- } \\
\text { sa-ni (L2), Jung-bang-dong-sa-ni (L3, O) }\end{array}$ \\
\hline $\begin{array}{l}\text { C. sanguinolentus Vahl } \\
\text { (= Pycreus sanguinolentus (Vahl) Nees) }\end{array}$ & - & - & - & - & - & - & $\begin{array}{l}\text { Bang-dong-san-i-dae-ga-ri } \quad(\mathrm{C}), \quad \text { Bang-dong-sa-ni- } \\
\text { dae-ga-ri }(\mathrm{L} 1, \mathrm{~L} 2, \mathrm{~L} 3, \mathrm{O})\end{array}$ \\
\hline Subgenus Cyperus & & & & & & & \\
\hline C. amuricus Maxim. & $\bullet$ & - & $\bullet$ & $\bullet$ & - & $\bullet$ & Bang-dong-san-i (C), Bang-dong-sa-ni (L1, L2, O) \\
\hline var. laxus (Franch. \& Sav.) Nakai & - & 0 & - & - & - & - & \\
\hline $\begin{array}{l}\text { C. cyperoides } \text { (L.) Kuntze } \\
\text { (= Mariscus cyperoides (L.) Momin) }\end{array}$ & - & - & - & - & - & $\begin{array}{lll}0 & 1 \\
- & j\end{array}$ & $\begin{array}{l}\text { Bang-dong-san-i-a-jae-bi (C), Bang-dong-sa-ni-a- } \\
\text { jae-bi }(\mathrm{L} 1, \mathrm{~L} 2, \mathrm{~L} 3, \mathrm{O})\end{array}$ \\
\hline $\begin{array}{l}\text { C. exaltatus Retz. var. iwasakii (Makino) } \\
\text { T. Koyama }\end{array}$ & $0^{1965}$ & - & ? & 0 & 0 & 0 & Wang-gol (L1, L2, L3, O) \\
\hline (= C. iwasakii Makino) & $0^{1944}$ & - & - & - & - & - & \\
\hline C. glomeratus $\mathrm{L}$. & 0 & ○ & ○ & 0 & 0 & - 1 & Mul-bang-dong-sa-ni (C, L1, L2, L3, O) \\
\hline C. iria $\mathrm{L}$. & ○ & ○ & - & ○ & 0 & - & $\begin{array}{l}\text { Cham-bang-dong-san-i (C), Cham-bang-dong-sa-ni } \\
(\mathrm{L} 1, \mathrm{~L} 2, \mathrm{~L} 3, \mathrm{O})\end{array}$ \\
\hline C. microiria Steud. & 0 & ○ & ○ & ○ & ○ & - & $\begin{array}{l}\text { Geum-bang-dong-sa-ni (C, L1, L2, O), Bang-dong- } \\
\text { sa-ni (L3) }\end{array}$ \\
\hline $\begin{array}{l}\text { C. orthostachyus Franch. \& Sav. } \\
\text { var. robustus (Nakai) Hara }\end{array}$ & - & - & - & - & - & - & $\begin{array}{l}\text { Soe-bang-dong-san-i (C), Soe-bang-dong-sa-ni (L1, } \\
\text { L2, L3, O) }\end{array}$ \\
\hline $\begin{array}{l}\text { C. rotundus L. } \\
\text { Subgenus Pycnostachys }\end{array}$ & 0 & 0 & 0 & 0 & 0 & 0 & Hyang-bu-ja (C, L1, L2, L3, O) \\
\hline C. difformis $\mathrm{L}$. & 0 & 0 & 0 & ○ & 0 & & $\begin{array}{l}\text { Al-bang-dong-san-i (C), Al-bang-dong-sa-ni (L1, L2, } \\
\mathrm{L} 3, \mathrm{O})\end{array}$ \\
\hline $\begin{array}{l}\text { C. flaccidus R.Br. } \\
\text { (= C. hakonensis Franch. \& Sav.) }\end{array}$ & - & - & - & - & - & -1 & $\begin{array}{l}\text { Byeong-a-ri-bang-dong-san-i (C), Byeong-a-ri-bang- } \\
\text { dong-sa-ni }(\mathrm{L} 1, \mathrm{~L} 2, \mathrm{~L} 3, \mathrm{O})\end{array}$ \\
\hline
\end{tabular}


Table 1. Continued.

\begin{tabular}{|c|c|c|c|c|c|c|c|}
\hline Taxon & $\begin{array}{c}\text { Ohwi } \\
(1944, \\
1965)\end{array}$ & $\begin{array}{l}\text { Chung } \\
(1957)\end{array}$ & $\begin{array}{l}\text { Lee } \\
(1996)(\end{array}$ & $\begin{array}{l}\text { Lee } \\
(2003)(\end{array}$ & $\begin{array}{l}\text { Lee } \\
(2006)\end{array}$ & $\begin{array}{l}\mathrm{Oh} \\
(2007)\end{array}$ & Korean name (Reference) \\
\hline C. haspan $\mathrm{L}$. & 0 & - & 0 & O & O & 01 & Mo-gi-bang-dong-sa-ni (L1, L2, L3, O) \\
\hline C. tenuispica Steud. & ○ & & ○ & ○ & ○ & - & U-san-bang-dong-sa-ni (L1, L2, L3, O) \\
\hline C. pacificus (Ohwi) Ohwi & 0 & - & 0 & ○ & ○ & $s$ & Seo-ul-bang-dong-sa-ni (L1, L2), Huin-bang-dong- \\
\hline $\begin{array}{l}(=C . \text { michelianus Link var. pacificus } \\
\text { Ohwi) }\end{array}$ & - & - & - & - & - & 0 & sa-ni $(\mathrm{L} 3, \mathrm{O})$ \\
\hline $\begin{array}{l}\text { C. nipponicus Franch. \& Sav. } \\
\text { (= Juncellus nipponicus (Fr. \& Sav.) C. B. } \\
\text { Clarke) }\end{array}$ & - & - & - & - & - & $\begin{array}{lll}0 & 1 \\
- & (\end{array}$ & $\begin{array}{l}\text { Na-do-bang-dong-san-i (C), Na-do-bang-dong-sa-ni } \\
\text { (L1, L2), Pu-reun-bang-dong-sa-ni (L3, O) }\end{array}$ \\
\hline \multicolumn{8}{|l|}{ Subgenus Juncellus } \\
\hline $\begin{array}{l}\text { C. serotinus Rottb. } \\
\begin{array}{llll}(=\text { Juncellus } & \text { serotinus } \quad \text { (Rottb.) C.B. } \\
\text { Clarke) } & & \end{array}\end{array}$ & - & - & - & - & - & $\begin{array}{lll}0 & 1 \\
- & \mathbf{r}\end{array}$ & $\begin{array}{l}\text { Neo-do-bang-dong-san-i (C), Neo-do-bang-dong-sa- } \\
\text { ni (L1, L2, L3), Kkot-bang-dong-sa-ni (O) }\end{array}$ \\
\hline \multicolumn{8}{|l|}{ Subgenus Diclidium } \\
\hline $\begin{array}{l}\text { Not distributed in South Korea } \\
\text { Genus Kyllinga Rottb. }\end{array}$ & - & - & - & - & - & - & \\
\hline K. brevifolia Rottb. & - & - & - & - & - & - & Ga-si-pa-dae-ga-ri $(O)$ \\
\hline var. leiolepis (Franch. \& Sav.) Hara & - & - & - & $\bullet$ & - & $-\quad \mathbf{I}$ & Pa-dae-ga-ri (C, L1, L2, L3) \\
\hline $\begin{array}{l}\text { (= K. brevifolia } \text { Rottb. subsp. leiolepis } \\
\text { (Franch. \& Sav.) T. Koyama) }\end{array}$ & - & - & - & - & $\bullet$ & - & \\
\hline $\begin{array}{l}(=\text { C. } \text { brevifolius (Rottb.) Hassk. var. } \\
\text { leiolepis }(\text { Fr. \& Sav. }) \text { T. Koyama) }\end{array}$ & 0 & - & $\bullet$ & - & - & - & \\
\hline $\begin{array}{l}\text { (? K. brevifolia Rottb. var. leiocarpa } \\
\text { (Franch. \& Sav.) Hara) }\end{array}$ & - & $\bullet$ & - & - & - & - & \\
\hline \multicolumn{8}{|l|}{ Genus Lipocarpha R. Br. } \\
\hline L. microcephala (R. Br.) Kunth & $\bullet$ & $\bullet$ & $\bullet$ & $\bullet$ & $\bullet$ & - $\mathrm{s}$ & Se-dae-ga-ri (C, L1, L2, L3, O) \\
\hline $\begin{array}{l}\text { No. of recognized taxa (genera/species/ } \\
\text { infraspecific taxa) }\end{array}$ & $2 / 21 / 2$ & $6 / 15 / 32$ & $2 / 21 / 23$ & $3 / 20 / 23$ & $3 / 19 / 2$ & $3 / 20 / 2$ & \\
\hline
\end{tabular}

군을 대상으로 잎의 표피형과 잎과 줄기의 단면 구조를 포함한 해부학적 형질을 상세히 분석되었으나 광합성 경 로의 유형은 고려되지 않았다(Oh et al., 1999). 분자계통학 적 연구로는 핵의 rDNA internal transcribed spacer (nrITS), 엽록체의 $r b c L$ 유전자와 $\operatorname{trnL}-F$ 구간을 이용하여 사초과 의 전체적인 계통과 국내 종의 계통학적 위치를 파악하는 과정에서 우리나라 방동사니속 식물이 포함되어 다루어 진 바가 있다(Jung and Choi, 2013). 사초과의 광합성 경로 에 관해서는 $\mathrm{C} 4$ 식물인 참방동사니(Cyperus iria L.)와 C3 식물인 대사초(Carex siderosticta Hance)에 대하여 잎의 미 세구조가 비교되었다(Kim et al., 1999).

본 연구에서는 해부학적 관찰을 통해 우리나라에 분포하
는 방동사니속과 근연속 식물의 광합성 경로를 파악하고, 분자계통학적 유연관계와 함께 비교 분석하고자 하였다.

\section{재료 및 방법}

본 연구의 해부학적 관찰과 염기서열 결정에는 아주대 학교 표본관(AJOU)에 소장된 석엽표본을 이용하였으며, 광의의 방동사니속 18 종과 근연속에 속하는 파대가리와 세대가리를 포함하여 총 20 종을 대상으로 하였다 (Appendix 1).

해부학적 관찰을 위하여 석엽표본에서 분리한 잎이나 화서의 포는 $0.1 \mathrm{~N} \mathrm{NaOH}$ 수용액에 1시간 동안 담가두었 
다가, 조직이 충분이 부푼 후에 증류수에 1 시간씩 2 회의 세척과정을 통해 재수화하여 사용하였다(Shobe and Lersten, 1967). 재수화된 조직은 슬라이드글라스 위에서 면도날을 이용해 얇은 절편으로 자른 후, 실체현미경에서 광합성 조직의 분포('Kranz anatomy')에 따라 광합성 경로 의 유형을 결정하였다.

우리나라 방동사니속 식물의 분자계통학적 위치를 결 정하고, 광합성경로와의 비교를 위하여 nrITS, 엽록체의 $r b c L$ 유전자, $t r n L-F$ 구간의 염기서열을 결정하였다. DNA 는 석엽표본이나 $-70^{\circ} \mathrm{C}$ 에 보관된 조직으로부터 $\mathrm{CTAB}$ 방 법을 이용하여 추출되었다(Chen and Ronald, 1999). 목적부 위의 증폭과 염기서열 결정을 위해 사용된 프라이머는 nrITS의 경우 P1과 P4 (White et al., 1990), $r b c L$ 은 $1 \mathrm{~F}$ 와 636F (Muasya et al., 1998), 778R과 1400R (Jung and Choi, 2010), trnL $-F$ 구간은 c와 $\mathrm{f}$ (Taberlet et al., 1991), 647F 와 696R (Jung and Choi, 2011)이다. 각 부위의 증폭조건은 선행된 연구에서 제시한 바에 따랐다(Jung and Choi, 2013). 증폭 된 산물은 $\mathrm{Gel} \& \mathrm{PCR}$ 정제 키트(SolGent)로 정제한 후, BigDye Terminator v3.1 ready reaction mix (Applied Biosystems)와 ABI Prism 3730xl DNA analyzer (Applied Biosystems)를 이용하여 염기서열을 결정하였다.

분자계통의 추론에는 본 연구에서 새로이 분석된 5 종 12 개의 염기서열과 선행연구에서 분석된 78 분류군의 174 개 염기서열이 함께 분석되었다(Appendix 2). 각 부위의 염기서열은 MUSCLE (Edgar, 2004)을 이용하여 다중 정렬 하였으며, 이 과정에서 형성된 gap은 FastGap 1.2 (Borchsenius, 2009)을 이용하여 이진수 형질로 전환하였 다. 내군은 CYPERUS 분계군의 13 속 55 종(국내 3 속 20 분 류군)을 포함하였고, 외군으로는 사초과 전체의 계통분석 에서 자매군으로 나타난 FICINIA 분계군의 5속 23종을 사 용하였다(Muasya et al., 2009b; Jung and Choi, 2013). 계통분 석에는 최대절약법(maximum parsimony method)과 베이즈 추론(Bayesian inference)을 이용하여 각 염기서열 자료 $(\mathrm{nrITS}$, 엽록체의 $r b c L$, 엽록체의 $t r n L-F)$ 에 대하여 분석한 후, 세 염기서열자료를 병합하여 분석하였다. 최대절약법 은 PAUP* 4.0b10 (Swofford 2002)을 이용하였고, 최소형질 변화 단계를 가진 계통수를 탐색하기 위해 heuristic search 를 사용하였다. 계통수 탐색조건으로 simple addition sequence replicates, tree-bisection-recombination branch swapping을 설정하였고, 최대저장계통수의 수는 10,000 개 로 제한하였다. 계통수의 길이와 일관성지수(consistency index, CI), 유지지수(retention index, RI)는 PAUP* 4.0b10 (Swofford, 2002)을 이용하여 구하였다. 각 branch의 지지도 를 파악하기 위하여 bootstrap 분석(BS)을 1,000 회 반복 실 시하였으며, 분석조건은 최대저장계통수의 수를 1,000 개 로 제한한 것을 제외하고 최대절약법의 계통수 탐색조건 과 동일하다.

베이즈 추론에 근거한 계통수 작성을 위해, MrModeltest
2.3 (Nylander, 2004)과 PAUP* 4.0b10 (Swofford, 2002)를 사 용해 세 염기서열 구간에 대한 염기치환 모델을 검토하고, Akaike information criterion (Posada and Buckley, 2004)에 따 라서 선택하였다. 베이즈 추론은 MrBayes v3.2 (Ronquist and Huelsenbeck, 2003)를 이용하여 수행하였으며, 각 구간 에 대하여 선택된 염기치환모델을 적용하여 수행하였다. 두 개의 독립적인 Markov Chain Monte Carlo run을 수행하 였고, 각 run에는 4 개의 chain이 포함되었으며, $1 \times 10^{7}$ 회를 진행하였다. 매 1,000 회 마다 각 'run'에서 계통수를 취하 였고, 그 중 $30 \%$ 의 계통수는 우도(likelihood) 그래프와 split frequency에 따라서 'burn-in'과정에서 제외되었다. 나 머지 계통수를 이용하여 $50 \%$ 합의계통수를 작성하고 사 후확률(posterior probability, PP)을 구하였다.

\section{결 과}

\section{해부학적 관찰에 의한 광합성 경로의 결정}

방동사니속 18 종과 근연속인 파대가리속 1 종, 세대가 리속 1 종 총 20 종의 잎이나 화서의 포에서 횡단면의 광합 성 조직 분포 형태에 따라서 각 식물의 광합성 경로(즉, $\mathrm{C} 3$ 식물과 $\mathrm{C} 4$ 식물)를 파악하였다. 이 중 16 종은 유관속 주위 에 엽록체가 집중된 것으로 관찰되어 $\mathrm{C} 4$ 식물로 결정되었 고, 나머지 4종은 엽록체가 표피 아래의 엽육 조직에 분포 하는 것으로 확인되어 C3 식물로 결정하였다(Fig. 1). 분류 군 별로는 방동사니속의 5개 아속 중에서 Pycreus아속에 속하는 3종(드렁방동사니 Cyperus flavidus Retz., 갯방동사 니 C. polystachyos Rottb., 방동사니대가리 C. sanguinolentus Vahl)은 C4 식물이었다(Fig. 1A-C). Cyperus아속의 8종[방 동사니 C. amuricus, 방동사니아재비 C. cyperoides (L.) Kuntze, 왕골 C. exaltatus Retz. var. iwasakii (Makino) T. Koyama, 물방동사니 C. glomeratus L., 참방동사니, 금방동 사니 C. microiria Steud., 쇠방동사니 C. orthostachyus Franch. \& Sav., 향부자 C. rotundus L.]은 모두 C4 식물이었 다(Fig. 1D-K). Pycnostachys아속의 6종 중 4종(알방동사니 C. difformis L., 병아리방동사니 C. flaccidus R. Br., 모기방 동사니 C. haspan L., 우산방동사니 C. tenuispica Steud.)은 $\mathrm{C} 3$ 식물로 확인되었다(Fig. 1L-O). Pycnostachys아속의 나 머지 2종[서울방동사니 C. pacificus (Ohwi) Ohwi, 나도방 동사니 C. nipponicus Franch. \& Sav.]은 C4 식물로 확인되 었다(Fig. 1P, Q). Juncellus 아속의 너도방동사니(C. serotinus Rottb.)는 C4 식물로 결정되었다(Fig. 1R). 파대가 리속의 파대가리와 세대가리속의 세대가리도 모두 $\mathrm{C} 4$ 식 물로 확인되었다(Fig. 1S, T).

\section{방동사니족(Cypereae) 식물의 분자계통분류학적 유 연관계}

외군(FICINIA 분계군)을 제외한 내군(CYPERUS 분계 군)에서 nrITS 염기서열은 $549-594 \mathrm{bp}$ 의 길이변이가 있었 

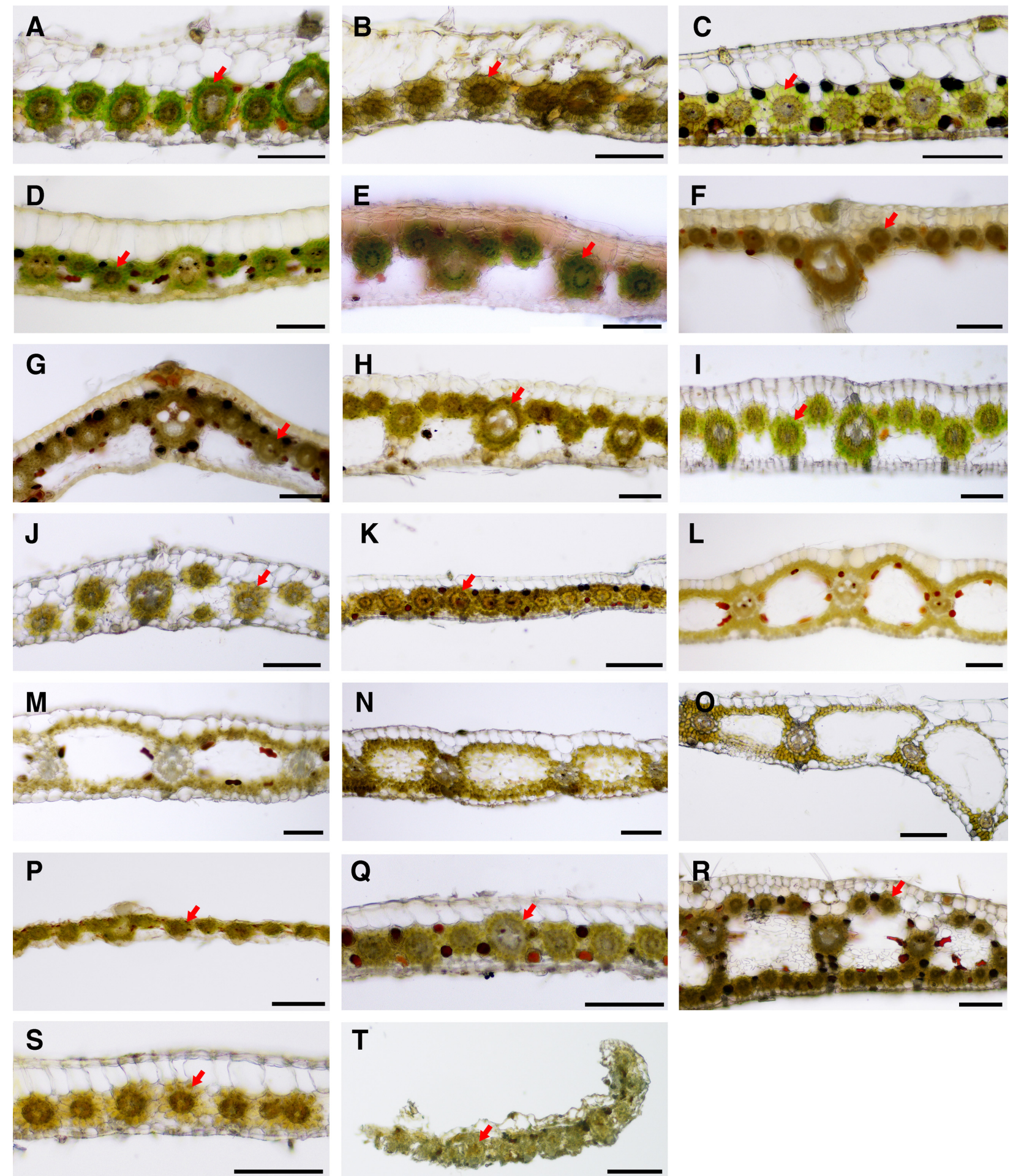

Fig. 1. Determination of photosynthesis pathway based on the presence or absence of Kranz anatomy. Twenty species of Cyperus L. and the two related genera (Kyllinga Rottb. and Lipocarpha R. Br.) were examined by cross section of leaf or leafy bract. A. C. flavidus Retz. (C4). B. C. polystachyos Rottb. (C4), C. C. sanguinolentus Vahl (C4). D. C. amuricus Maxim. (C4). E. C. cyperoides (L.) Kuntze (C4). F. C. exaltatus Retz. var. iwasakii (Makino) T. Koyama (C4). G. C. glomeratus L. (C4). H. C. iria L. (C4). I. C. microiria Steud. (C4). J. C. orthostachyus Franch. \& Sav. (C4). K. C. rotundus L. (C4). L. C. difformis L. (C3). M. C. flaccidus R. Br. (C3). N. C. haspan L. (C3). O. C. tenuispica Steud. (C3). P. C. pacificus (Ohwi) Ohwi (C4). Q. C. nipponicus Franch. \& Sav. (C4). R. C. serotinus Rottb. (C4). S. Kyllinga brevifolia Rottb. var. leiolepis (Franch. \& Sav.) Karthik. (C4). T. Lipocarpha microcephala (R. Br.) Kunth (C4). The red arrows indicate photosynthetic tissue concentrated around bundle in C4 plant. Length of scale bars are $100 \mu \mathrm{m}$. 
Table 2. Statistics of nrITS, $r b c L$, $\operatorname{trn} L-F$, and combined data set used in the molecular phylogenetic analyses.

\begin{tabular}{lcccc}
\hline \hline \multicolumn{1}{c}{ Characteristic } & nrITS & $r b c L$ & trnL-F & $\begin{array}{c}\text { Combined } \\
\text { data set }\end{array}$ \\
\hline Number of operational taxonomic units & 41 & 78 & 67 & 78 \\
Aligned length (after gap coding) & $629(694)$ & $1,291(1,291)$ & $1,306(1,625)$ & $3,226(3,610)$ \\
Number of variable characters (\%) & $407(58.6)$ & $176(13.6)$ & $801(49.3)$ & $1,384(38.3)$ \\
Number of parsimonious informative characters (\%) & $307(44.2)$ & $99(7.6)$ & $342(21.0)$ & $719(19.9)$ \\
Number of most parsimonious trees & 3 & $>10,000$ & 5,773 & $>10,000$ \\
Length of tree & 1,035 & 293 & 1,332 & 2,726 \\
Consistency index (CI) & 0.5712 & 0.6984 & 0.6664 & 0.6145 \\
Retention index (RI) & 0.8376 & 0.8998 & 0.7386 & 0.8029 \\
Nucleotide substitution model & GTR $+\Gamma$ & HKY $+\mathrm{I}+\Gamma$ & $\mathrm{HKY}+\Gamma$ & - \\
\hline
\end{tabular}

nrITS: internal transcribed spacer of nuclear rDNA.

으며, 쇠방동사니가 가장 짧았고 병아리방동사니가 가장 길었다(Table 2). nrITS 염기서열을 다중정렬을 하였을 때 $629 \mathrm{bp}$ 였고, gap coding후에는 694개 형질로 전환되었다 (Table 2). 이 중 407 개(58.6\%)에서 변이가 있었으며 307 개 (44.2\%)가 최대절약분석에 유효한 형질이었다(Table 2). 엽록체 $r b c L$ 유전자 염기서열은 $1,291 \mathrm{bp}$ 로 일정하였으나, 외군으로 포함된 Isolepis marginata (Thunb.) A. Dietr.의 $r b c L$ 유전자에만 $3 \mathrm{bp}$ 의 결실이 있다(Table 2). 정렬 후에도 I. marginata를 제외한 다른 종에서는 gap이 발생하지 않았 으며, 176 개(13.6\%)가 변이형질, 99 개(7.6\%)가 유효형질이 었다(Table 2). 엽록체 $t r n L-F$ 구간의 염기서열은 $805 \mathrm{bp}$ (C. laevigatus $\mathrm{L}$.)-1,008 bp (우산방동사니)의 길이변이가 있었으며, 다중정렬을 하였을 때 $1,306 \mathrm{bp}$ 였고, gap coding 후에는 1,625 개 형질로 전환되었으며, 이 중 801 개 (49.3\%)의 변이가 있었으며 342 개(21.0\%)가 유효한 형질 이었다(Table 2).

nrITS 염기서열자료에 근거해서 탐색한 최대절약계통 수는 3개(1,033 steps)였고, 엽록체 $r b c L$ 유전자 자료에서는 $293 \mathrm{step}$ 을 가진 계통수가 10,000 개 이상 추정되었으며, 엽 록체 $\operatorname{trnL}-F$ 구간의 경우에는 5,773 개(1,332 steps)가 구해졌 다(Table 2). 세 염기서열자료를 병합한 자료를 최대절약법 으로 분석한 결과 $2,726 \mathrm{step}$ 을 가진 계통수 $(\mathrm{CI}=0.6145$, $\mathrm{RI}=0.8029)$ 가 10,000 개 이상 나타났다(Table 2).

최대절약분석법에 의해 세 구간의 염기서열로부터 각 각 추정된 모든 합의계통수에서 FICINIA 분계군과 CYPERUS 분계군은 뚜렷이 구분되었으나, 방동사니속 및 근연속들의 유연관계에 대해서는 해상력이 낮게 나타 났다(자료 생략).

베이즈 추론에 의한 $50 \%$ 합의계통수에서 나타난 분계 군들을 사후확률과 최대절약분석법에서 적용된 부트스트 랩으로 평가한 결과, 방동사니족 내의 FICINIA 분계군과 CYPERUS 분계군의 구분은 강하게 지지되었다 $(\mathrm{PP}=1.00$,
$\mathrm{BS}=98$ ) (Fig. 2). CYPERUS 분계군 내에서 세대가리속 $(\mathrm{PP}=1.00, \mathrm{BS}=88)$ 과 Ascolepis 속 $(\mathrm{PP}=1.00, \mathrm{BS}=86)$ 은 단계통 을 형성하였고 잘 지지되었지만, 방동사니속과 파대가리 속, Kyllingiella속, Alinula속은 단계통을 형성하지 못하였 다(Fig. 2). 우리나라 방동사니속 식물 중 Pycnostachys아속 에 속하는 병아리방동사니, 모기방동사니, 우산방동사니 는 가까운 유연관계를 나타내었고 강하게 지지되었으며 $(\mathrm{PP}=1.00, \mathrm{BS}=97)$, 같은 아속의 알방동사니는 $C$. dichrostachyus Hochst. ex A.Rich와 가깝게 나타났다(Fig. 2). Pycreus 아속의 3종(드렁방동사니, 갯방동사니, 방동사니 대가리)이 포함된 분계군은 금방동사니(Cyperus 아속)를 제외하고는 모두 Pycreus아속의 종들로 구성되었지만 약 하게 지지되었다( $\mathrm{PP}=0.65, \mathrm{BS}<50$ ) (Fig. 2). Cyperus아속에 속한 종들은 뚜렷한 분계군을 형성하지 못하였고 산재되 어 있었으며, 나도방동사니와 서울방동사니만 강한 유연 관계를 보였다( $\mathrm{PP}=1.00, \mathrm{BS}=100)$ (Fig. 2). Juncellus아속의 너도방동사니는 쇠방동사니(Cyperus아속)의 자매군으로 나타났고 강하게 지지되었다( $\mathrm{PP}=1.00, \mathrm{BS}=97)$ (Fig. 2).

\section{고 찰}

\section{한국산 방동사니족 식물의 광합성 경로와 분류}

방동사니족에서 일어난 광합성 경로의 전환은 사초과 에서 일어난 네 번의 독립적인 $\mathrm{C} 4$ 식물 출현 중 하나로서 (Sage, 2004), 현재까지 알려진 바로는 CYPERUS 분계군 에서 C3 식물인 Kyllingiella polyphylla (A. Rich.) Lye의 분기 이후 Cyperus cuspidatus Kunth와 나머지 C4 식물의 공통조 상에서 변화가 일어난 것으로 보여지며, 이후 이로부터 분화한 무리를 C4 분계군으로 칭한다(Larridon et al., 2011) (Fig. 2). 해부학적 관찰을 통해 우리나라의 방동사니속 식 물 4종은 $\mathrm{C} 3$ 식물로 확인되었으며, 나머지 14 종은 $\mathrm{C} 4$ 식 물로 관찰되었다(Fig. 1). 또한 세대가리와 파대가리는 $\mathrm{C} 4$ 


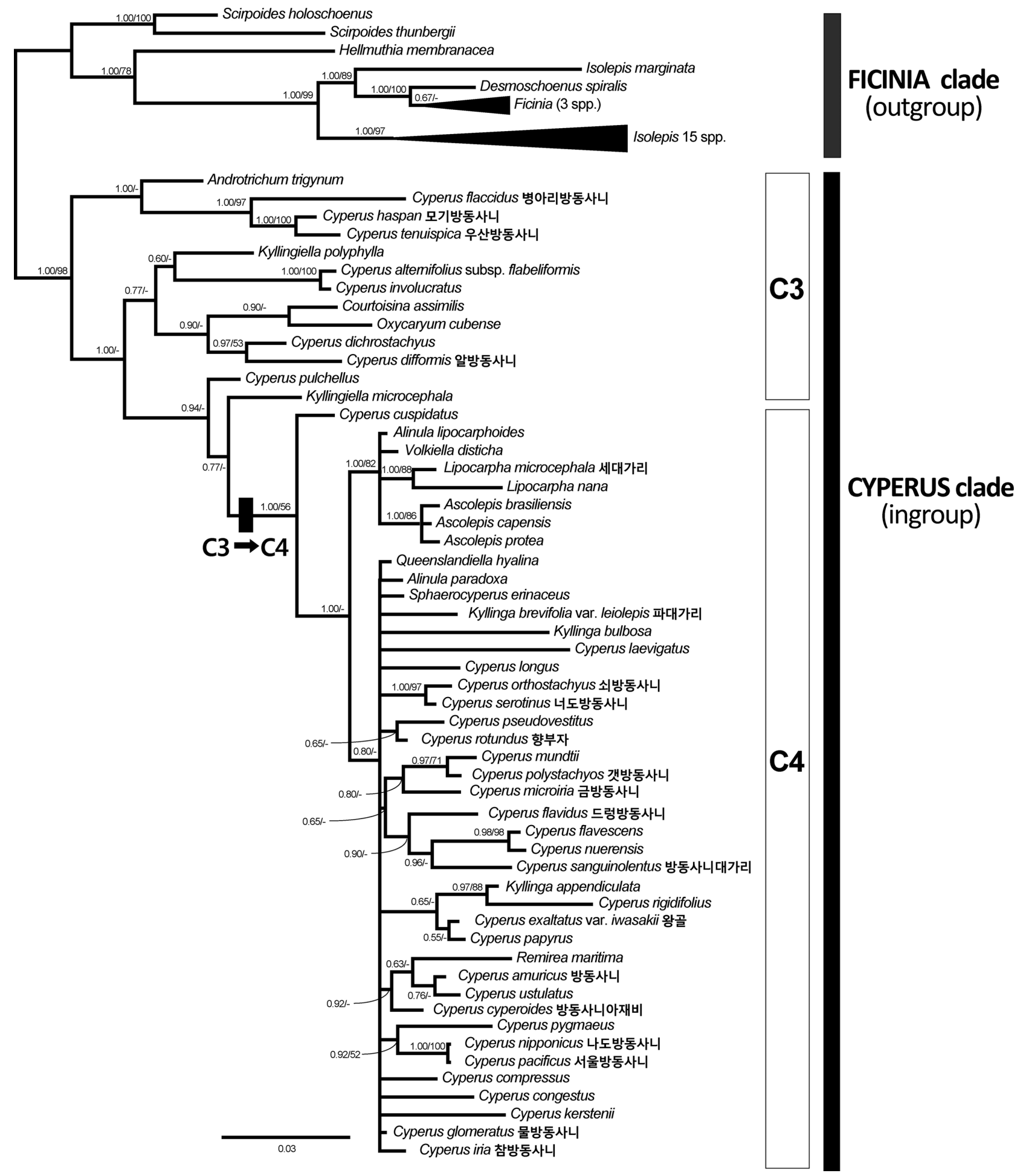

Fig. 2. Bayesian majority-rule (50\%) consensus tree with mean branch lengths based on combined data set of nrITS, $r b c L$, and $t r n L-F$ from 78 species of the tribe Cypereae $(-\ln \mathrm{L}=19,703.289)$. Numbers at branches indicate support values (Bayesian posterior probability [PP]/ maximum parsimony bootstrap value [BS]). Twenty Korean Cypereae are shown with a black rectangle. Scale bar represents expected changes per site.

식물로 확인되었다(Fig. 1). 우리나라의 방동사니속 식물 중 C3 광합성 경로를 지닌 식물은 Pycnostachys아속에 속
하는 병아리방동사니, 모기방동사니, 우산방동사니, 알방 동사니이다(Figs. 1L-O, 2). 이 중 3종(병아리방동사니, 모 
기방동사니, 우산방동사니)은 엽신이 잘 발달하지 않고 납작한 소수가 수지상으로 달리는 형태적 특징이 있고, Haspani절과 일치한다. 그에 비하여 알방동사니는 일년생 이고 매우 작은 인편과 수과로 구별되는 Fusci절에 속한다 (Larridon et al., 2011). Pycnostachys아속의 나머지 두 종(서 울방동사니, 나도방동사니)은 $\mathrm{C} 4$ 식물로 확인되었는 데 (Fig. 1P, Q), 소수가 덜 납작하고 두상으로 밀집되어 달리 며, 인편이 다소 나선상으로 배열하는 특징 때문에 Dichostylis절로 구분되기도 하였다(Ohwi, 1944). 또한 이 두 종은 다른 방동사니속 식물들의 주두가 2 개 또는 3 개 로 확연히 구별되는 것과는 달리 주두가 2-3개로 갈라지 는 특징을 공유하며(Ohwi, 1944), 분자계통분석에서도 뚜 렷한 유연관계를 보였다(Fig. 2). C4 분계군내 다른 종들에 서는 형태학적 특징과 분자계통과의 관계가 명확하게 파 악되지 않는다(Fig. 2).

\section{방동사니족에서 속의 한계와 분자계통학적 유연관계}

방동사니족은 20 개 속 1,000 여 종을 포함하는데, 연구 자에 따라 FICINIA 분계군에 포함된 8개 속을 별개의 족 (즉, Ficineae)으로 다루거나 인편이 나선형으로 배열하는 점을 들어 고랭이족(Scirpeae)에 포함시키기도 하였다 (Bruhl, 1995). 그러나 많은 분자계통학적 증거들에 근거하 여 FICINIA 분계군이 CYPERUS 분계군의 자매군으로서 방동사니족에 포함되며, 두 분계군의 구분은 본 연구결과 에서도 잘 지지되었다(Muasya et al., 2009a, 2009b; Jung and Choi, 2013) (Fig. 2). 방동사니족에서 5종 미만의 종들로 구 성된 속은 15 개 속이며 주요 5 개 속(Ascolepis 22종, 방동사 니속 812종, 파대가리속 73종, 세대가리속 36종, Ficinia 74 종)에 대부분의 종들이 속해있다(Goetghebeur, 1998; Govaerts et al., 2007). 최근 사초과의 분류체계에서 적은 수 의 종을 포함한 속들에 대하여 많은 재검토가 이루어지고 있다. 그 예로서 한 종으로만 구성된 FICINIA 분계군의 Desmoschoenus Hook. f. 속은 분자계통학적 연구결과에서 Ficinia속과 함께 단계통을 형성하여 속의 재설정 주장된 바 있다(Muasya and Lange, 2010).

우리나라 종들이 포함된 CYPERUS 분계군내의 분류체 계는 보다 유동적이다. 그 예로서 Hemicarpha Nees속과 Rikliella J. Raynal속은 독립된 속으로 다루어지기도 하였 지만, 발생학적 증거에 따라 세대가리속에 포함시켰다 (Goetghebeur, 1998). 최근에는 더 나아가 형태 및 발생학적 증거와 분자계통학적 증거를 바탕으로 세대가리속과 Hemicarpha속, Rikliella속 전체를 방동사니속 내 절 수준 으로 포함하자는 의견도 제시되었다(Bauters et al., 2014). 파대가리속이나 세대가리속의 경우 본 연구 결과와 기존 의 몇몇 연구에서 각각 단계통을 형성하지 못하였다 (Muasya et al., 2009a, 2009b; Jung and Choi, 2013) (Fig. 2). 반면 상대적으로 해상력이 높은 것으로 알려진 핵의 ETS1f와 엽록체의 $t r n H-p s b A, r p l 32-t r n L$ 구간의 염기서열
을 이용한 최근의 연구에서는 방동사니속 식물에 둘러 싸 이긴 하지만 파대가리속 식물은 단계통을 형성하였고, 세 대가리속도 Volkiella Merxm.속을 포함하여 단계통을 형성 하였다(Larridon et al., 2013).

방동사니속이 측계통이라는 분자계통학적 증거는 지 속적으로 제시되어 왔으며, 본 연구결과와 모든 분자계 통연구에서 제시된 계통수에서 방동사니속 식물이 CYPERUS 분계군 전체에 산재되어 있는 것으로 나타났 다(Muasya et al., 2009a, 2009b; Jung and Choi, 2013; Larridon et al., 2013) (Fig. 2). 방동사니속은 Pycreus속과 협의의 방동사니속으로 나누어 보는 견해가 있는데, Pycreus속의 형태적 특징은 두 개로 갈라진 주두와 소수 의 축에 대해서 세로로 납작한 수과이며, 협의의 방동사 니속은 세 개(간혹 두 개)로 갈라진 주두와 삼릉형이거나 축에 대해서 가로로 납작한 수과를 특징으로 한다 (Goetghebeur, 1998, Muasya et al., 2001). Pycreus속은 분자 계통수에서 몇몇 협의의 방동사니속 식물과 함께 분계군 을 형성하지만 강하게 지지되지는 않는다(Larridon et al., 2013) (Fig. 2).

현재까지 CYPERUS 분계군의 분자계통수에서 도출된 속을 대표하는 분계군들은 모두 방동사니속의 종들에 의 해 둘러 싸여 계통학적 측면에서는 독립된 속의 지위를 부여하기가 어렵다. 따라서 분자계통학적 증거와 분류체 계를 일치시키기 위해서는 12 개 속이 포함된 CYPERUS 분계군을 하나의 방동사니속으로 인정하거나, 많은 수의 신속을 설정해야만 한다(Muasya et al., 2009b). 이에 대해 기존의 형태학적 속의 기준과 분자계통학적 유연관계를 절충한 속의 구분이 제시되었지만(Muasya et al., 2009b), 최근에는 상세한 분자계통연구와 더불어 발생학적 증거 들을 통해 기존의 속들을 광의의 방동사니속의 아속이나 절 수준의 속내 분류군으로 포함하는 의견이 제시되고 있다(Larridon, 2011; Larridon et al. 2013; Bauters et al., 2014). 다만, $\mathrm{C} 4$ 분계군 내에서는 과거의 급격한 종분화 과정 때문에 분자계통수의 해상력이 낮고(Sage, 2004; Besnard et al. 2009) (Fig. 2), 사후확률이나 부트스트랩 평 가에 의해 강한 지지를 받지 못하여 속내 분류체계를 확 정하기에도 어려움이 있다(Muasya et al., 2009a, 2009b; Larridon et al., 2013). 따라서 C4 분계군에 속한 종들의 유 연관계를 파악하여 방동사니족(Cypereae, Cyperaceae)의 분류체계를 정립하기 위해서는 많은 종의 검토와 형태학 적, 발생학적 연구와 더불어 해상력이 높은 염기서열 부 위를 이용한 면밀한 분자계통학적 분석이 필요한 것으로 여겨진다.

\section{사 사}

이 논문은 정부(교육부)의 재원으로 한국연구재단의 연 구비를 받아 수행되었습니다(NRF 2012R1A1A2008497). 


\section{Literature Cited}

Bauters, K., I. Larridon, M. Reynders, P. Asselman, A. Vrijdaghs, A. M. Muasya, D. A. A. Simpson and P. Goetghebeur. 2014. A new classification for Lipocarpha and Volkiella as infrageneric taxa of Cyperus s.l. (Cypereae, Cyperoideae, Cyperaceae): insights from species tree reconstruction supplemented with morphological and floral developmental data. Phytotaxa 166: 1-32.

Besnard, G., A. M. Muasya, F. Russier, E. H. Roalson, N. Salamin and P.-A. Christin. 2009. Phylogenomics of $\mathrm{C}_{4}$ photosynthesis in sedges (Cyperaceae): multiple appearances and genetic convergence. Molecular Biology and Evolution 26: 1909-1919.

Borchsenius, F. 2009. FastGap 1.2. Department of Biosciences, Aarhus University, Denmark. Retrieved Sep. 19, 2016, from http://www.aubot.dk/FastGap_home.htm.

Bruhl, J. J. 1995. Sedge genera of the world: relationships and a new classification of the Cyperaceae. Australian Systematic Botany 8: 125-305.

Chen, D.-H. and P. C. Ronald. 1999. A rapid DNA minipreparation method suitable for AFLP and other PCR applications. Plant Molecular Biology Reporter 17: 53-57.

Chung, T. 1957. Korean Flora. Shinjisa, Seoul, 1025 pp.

Clarke, C. B. 1908. New genera and species of Cyperaceae. Bulletin of Miscellaneous Information (Royal Gardens, Kew) Additional Series 8: 1-196.

Dengler, N. and T. Nelson. 1999. Leaf structure and development in C4 plants. In C4 Plant Biology. Sage, R. F. and R. K. Monson (eds.), Academic Press, San Diego, CA. Pp. 133-172.

Edgar, R. C. 2004. MUSCLE: multiple sequence alignment with high accuracy and high throughput. Nucleic Acids Research 32: 1792-1797.

Goetghebeur, P. 1998. Cyperaceae. In The Families and Genera of Vascular Plants. Vol. 4. Kubitzki, K. (ed.), Springer Verlag, Berlin. Pp. 141-190.

Govaerts, R., D. A. Simpson, P. Goetghebeur, K. L. Wilson, T. Egorova and J. Bruhl. 2007. World Checklist of Cyperaceae: Sedges. Royal Botanical Garden, Kew, 765 pp.

Jung, J. and H.-K. Choi. 2010. Systematic rearrangement of Korean Scirpus L. s.l. (Cyperaceae) as inferred from nuclear ITS and chloroplast $r b c L$ sequences. Journal of Plant Biology 53: $222-232$.

Jung, J. and H.-K. Choi. 2011. Taxonomic study of Korean Scirpus L. s.l. (Cyperaceae) II: Pattern of phenotypic evolution inferred from molecular phylogeny. Journal of Plant Biology 54: 409-424.

Jung, J. and H.-K. Choi. 2013. Recognition of two major clades and early diverged groups within the subfamily Cyperoideae
(Cyperaceae) including Korean sedges. Journal of Plant Research 126: 335-349.

Kim, I. S., J.-H. Pak, B.-B. Seo and S.-D. Song. 1999. Ultrastructure of leaves in $\mathrm{C}_{4}$ Cyperus iria and $\mathrm{C}_{3}$ Carex siderosticta. Journal of Plant Biology 42: 213-221.

Larridon, I. 2011. Exploring giant genera and their satellites, tales from the C3 Cyperus universe. PhD dissertation, Ghent University, Ghent, Belgium, 402 pp.

Larridon, I., M. Reynders, W. Huygh, K. Bauters, A. Vrijdaghs, O. Leroux, A. M. Muasya, D. A. Simpson and P. Goetghebeur. 2011. Taxonomic changes in $C_{3}$ Cyperus (Cyperaceae) supported by molecular data, morphology, embryography, ontogeny and anatomy. Plant Ecology and Evolution 144: 327-356.

Larridon, I., K. Bauters, M. Reynders, W. Huygh, A. M. Muasya, D. A. Simpson and P. Goetghebeur. 2013. Towards a new classification of the giant paraphyletic genus Cyperus (Cyperaceae): phylogenetic relationships and generic delimitation in $\mathrm{C}_{4}$ Cyperus. Botanical Journal of the Linnean Society 172: $106-126$.

Lee, K. B. 2004. Plant Anatomy. Lifescience Publishing Co., Seoul, $140 \mathrm{pp}$.

Lee, T. B. 2003. Coloured Flora of Korea. Hyang-Mun Publishing Co., Seoul, 914 pp.

Lee, W. T. 1996. Lineamenta Florae Koreae. Academy Press, Seoul. Pp. 1695-2383.

Lee, Y. N. 2006. New Flora of Korea. Kyo-Hak Publishing Co., Seoul, Vol. 1, 975 pp, Vol. 2, 885 pp.

Linnaeus, C. 1753. Species Plantarum. Ray Society, London, 176 pp.

Linnaeus, C. 1754. Genera Plantarum. Ray Society, Stockholm, 26 pp.

Muasya, A. M., D. A. Simpson, M. W. Chase and A. Culham. 1998. An assessment of suprageneric phylogeny in Cyperaceae using $r b c L$ DNA sequences. Plant Systematics and Evolution 211: 257-271.

Muasya, A. M., D. A. Simpson and M. W. Chase. 2001. Generic relationships and character evolution in Cyperus s.l. (Cyperaceae). Systematics and Geography of Plants 71: 539-544.

Muasya, A. M., D. A. Simpson and M. W. Chase. 2002. Phylogenetic relationships in Cyperus L. s.l. (Cyperaceae) inferred from plastid DNA sequence data. Botanical Journal of the Linnean Society 138: 145-153.

Muasya, A. M., D. Simpson, G. Verboom, P. Goetghebeur, R. F. C. Naczi, M. W. Chase and E. Smets. 2009a. Phylogeny of Cyperaceae based on DNA sequence data: current progress and future prospects. The Botanical Review 75: 2-21.

Muasya, A. M., A. Vrijdaghs, D. A. Simpson, M. W. Chase, P. Goetghebeur and E. Smets. 2009b. What is a genus in Cyper- 
eae: phylogeny, character homology assessment and generic circumscription in Cypereae. The Botanical Review 75: 5266.

Muasya, A. M. and P. J. de Lange. 2010. Ficinia spiralis (Cyperaceae) a new genus and combination for Desmoschoenus spiralis. New Zealand Journal of Botany 48: 31-39.

Nylander, J. A. A. 2004. MrModeltest 2.3. Evolutionary Biology Centre, Uppsala University, Uppsala.

Oh, Y. C., C. S. Lee and K. M. Ko. 1999. Anatomical study of Korean Cyperus Linne. Korean Journal of Plant Taxonomy 29: 325-354.

Oh, Y. C. and Y. H. Lee. 1999. A systematic study on Cyperus L. of Korea (Cyperaceae). Korean Journal of Plant Taxonomy 29: $37-62$.

Oh, Y. C. 2007. Cyperaceae. In The Genera of Vascular Plantd of Korea. Park, C.-W. (ed.), Academy Publishing Co., Seoul. Pp. 1113-1181.

Ohwi, J. 1944. Cyperaceae Japonicae, II. A synopsis of the Rhynchosporoideae and Scirpoideae of Japan, including the Kuriles, Saghalin, Korea, and Formosa. Memoirs of the College of Science; Kyoto Imperial University Series B, (botany, zoology, geology) biology 18: 1-182.

Ohwi, J. 1965. Flora of Japan. Shibundo, Tokyo, 1067 pp.

Posada, D. and T. R. Buckley. 2004. Model selection and model averaging in phylogenetics: Advantages of Akaike Information Criterion and Bayesian approaches over likelihood ratio tests. Systematic Biology 53: 793-808.

Ronquist, F. and J. P. Huelsenbeck. 2003. MrBayes 3: Bayesian phylogenetic inference under mixed models. Bioinformatics 19: 1572-1574.
Sage, R. F. 2004. The evolution of $\mathrm{C}_{4}$ photosynthesis. New Phytologist 161: 341-370.

Shobe, W. R. and N. R. Lersten. 1967. A technique for clearing and staining Gymnosperm leaves. Botanical Gazette 128: $150-152$.

Soros, C. L. and J. J. Bruhl. 2000. Multiple evolutionary origins of $\mathrm{C} 4$ photosynthesis in the Cyperaceae. In Monocots: Systematics and Evolution. Wilson, K. L. and D. A. Morrison (eds.), CSIRO Publishing, Melbourne. Pp. 629-635.

Swofford, D. L. 2002. PAUP*: Phylogenetic analysis using parsimony (*and other methods). Ver. 4.0b10. Sinauer Associates Inc., Sunderland, MA.

Taberlet, P., L. Gielly, G. Pautou and J. Bouvet. 1991. Universal primers for amplification of three non-coding regions of chloroplast DNA. Plant Molecular Biology 17: 1105-1109.

Tieszen, L. L., M. M. Senyimba, S. K. Imbamba and J. H. Troughton. 1979. The distribution of $\mathrm{C}_{3}$ and $\mathrm{C}_{4}$ grasses and carbon isotope discrimination along an altitudinal and moisture gradient in Kenya. Oecologia 37: 337-350.

Tucker, G. C., B. G. Marcks and J. R. Carter. 2002. Cyperus. In Flora of North America North of Mexico. Vol. 23. Flora of North America Editorial Committee (ed.), Oxford University Press, New York. Pp. 141-191.

White, T. J., T. Bruns, S. Lee and J. Taylor. 1990. Amplification and direct sequencing of fungal ribosomal RNA genes for phylogenetics. In PCR Protocols: A Guide to Methods and Applications. Innis, M. A., D. H. Gelfand, J. J. Sninsky and T. J. White (eds.), Academic Press, San Diego, CA, Pp. 315-322. 


\title{
Appendix 1. Information of vouchers used for the anatomical observation and the molecular phylogenetic study. All specimens are deposited in Herbarium of Ajou University (AJOU).
}

\begin{abstract}
Cyperus amuricus, KOREA, Chungcheongbuk-do: Yeongdong-gun, Mt. Cheonmansan, 13 Sep 2010, J. Jung 1009030; C. cyperoides, KOREA, Jeollanam-do: Jindo-gun, 23 Oct 2010, J. Jung 1010273; C. difformis, KOREA, Chungcheongnam-do: Taean-gun, Uihang-beach, 11 Aug 2008, J. Jung 808012; C. exaltatus var. iwasakii, KOREA, Incheon: Ganghwa-gun, Ganghwado Isl., 11 Aug 1992, H.-K. Choi s.n.; C. flaccidus, KOREA, Gangwon-do: Yanggu-gun, Soyan Lake, 24 Aug 2010, J. Jung 1008002; C. flavidus, KOREA, Jeollanam-do: Jindo-gun, Geumgye-ri, 23 Oct 2010, J. Jung 1010285; C. glomeratus, KOREA, Jeollabuk-do: Buan-gun, Chungho reservoir, 23 Sep 2009, J. Jung 909173; C. haspan, KOREA, Gyeongsangnam-do: Geoje-si, Beopdong-ri, 19 Oct 2010, J. Jung 1010177; C. iria, KOREA, Jeollabukdo: Gochang-gun, Yongdae reservoir, 23 Sep 2009, J. Jung 909166; C. microiria, KOREA, Gangwon-do: Yanggu-gun, Soyang lake, 24 Aug 2010, J. Jung 1008005; C. nipponicus, KOREA, Chungcheongnam-do: Seocheon-gun, Wolho-ri, 14 Sep 2010, J. Jung 1009073; C. orthostachyus, KOREA, Chungcheongbuk-do: Yeongdong-gun, Mt. Cheonmansan, 13 Sep 2010, J. Jung 1009032; C. pacificus, KOREA, Gyeonggi-do: Icheon-si Yongpung reservoir, 4 Jul 2008, J. Jung 807040; C. polystachyos, KOREA, Gyeonggi-do: Whaseong-si, Ujeongeup, 16 Sep 2010, J. Jung 1009077; C. rotundus, KOREA, Jeju-do: Jeju-si, Gujwa-eup, Haengwon-ri, 2 Nov 2010, J. Jung 1007126; C. sanguinolentus, KOREA, Chungcheongbuk-do: Yeongdong-gun, Mt. Cheonmansan, 13 Sep 2010, J. Jung 1009043; C. serotinus, KOREA, Gyeongsangnam-do: Geoje-si, Haksan-ri, 19 Oct 2010, J. Jung 1010170; C. tenuispica, CHINA, Chaling: Hunan, 17 Jul 2008, J. Jung 807091; Kyllinga brevifolia var. leiolepis, KOREA, Chungcheongbuk-do: Yeongdong-gun, Mt. Cheonmansan, 13 Sep 2010, J. Jung 1009007; Lipocarpha microcephala, KOREA, Gyeongsangbuk-do: Ulju-gun, Wangpi river, 6 Oct 2010, J. Jung 1010132.
\end{abstract}

\section{Appendix 2. GenBank accession numbers of DNA sequences (nrlTS/rbcL/trnL-F) used in the molecular phylogenetic analyses.}

Alinula lipocarphoides (-/AM999784/-), A. paradoxa (-/AJ278290/AJ295756), Androtrichum trigymum (-/EF178547/-), Ascolepis brasiliensis (-/AM999785/-), A. capensis (-/Y13003/AY040594), A. protea (-/Y13002/-), Courtoisina assimilis (-/AY040590/AY040595), Cyperus alternifolius subsp. flabeliformis (JX644851/JX644653/JX644796), C. amuricus (JX644852/JX644654/JX644799), C. compressus (-/AF449506/ AF449555), C. congestus (-/AM234972/AF449556), C. cuspidatus (-/AF449508/AF449557), C. cyperoides (JX644853/JX644655/JX644800), C. dichrostachyus (-/Y12965/-), C. difformis (JX644854/JX644656/-), C. exaltatus (-/JX644657/-), C. flaccidus (JX644855/JX644658/-), C. flavescens (-/Y13005/AJ295763), C. flavidus (JX644856/JX644659/JX644798), C. glomeratus (-/JX644660/-), C. haspan (JX644857/JX644661/ -), C. involucratus (AY242052/Y12967/AJ295758), C. iria (AB261666/AM999807/-), C. kerstenii (-/Y13018/AY040597), C. laevigatus (-/ Y13017/-), C. longus (-/AM999810/AY040598), C. michelianus subsp. pygmaeus (-/AJ404698/AJ295760), C. microiria (JX644858/JX644662/ JX644801), C. mundtii (-/AF449517/AF449566), C. nipponicus (JX644859/JX644663/JX644804), C. merensis (-/Y13004/AY040603), C. orthostachyus (JX644860/JX644664/JX644802), C. pacificus (JX644861/JX644665/JX644805), C. papyrus (AY242048/AM999811/ AJ295759), C. polystachyos (JX644862/JX644666/JX644806), C. pygmaeus (-/AJ404698/AJ295760), C. pseudovestitus (-/AF449513/ AF449562), C. pulchellus (-/AM999812/-), C. rigidifolius (-/Y13016/AY040600), C. rotundus (-/JX644667/JX644807), C. sanguinolentus (JX644896/JX644701/AF449567), C. serotinus (JX644863/JX644668/JX644803), C. temuispica (JX644864/JX644669/JX644793), C. ustulatus (DQ385558/AM999816/-), Desmoschoenus spiralis (DQ385562/AJ404701/AJ295753), F. esterhuyseniae (GU012400/EF178549/EF178590), F. indica (GU012402/AM999831/EF178597), Hellmuthia membranacea (GU012384/AM999838/AJ295815), Isolepis aucklandica (DQ385573/AJ404704/AJ295773), I. cernua (DQ385576/AM999840/AF285070), I. costata (GU012414/Y12981/AJ295776), I. crassiuscula (AB261668/AB236355/AB236356), I. digitata (GU012415/AJ404708/AJ295779), I. habra (GU012386/AJ404710/AJ295783), I. hystrix (GU012388/AJ404711/AJ295785), I. inundata (DQ385581/AJ404712/AJ295786), I. levynsiana (-/AF449514/AF449563), I. marginata (GU012418/AJ404714/AJ295790), I. prolifera (DQ385584/AM999841/AJ295796), I. rubicunda (GU012420/AJ404719/AJ295797), I. sepulcralis (GU012391/AJ404720/AJ295798), I. setacea (JX644893/JX644698/JX644794), I. sulcata (GU012393/AJ404722/AJ295802), I. venustula (GU012421/AJ404724/AJ295804), Kyllinga appendiculata (-/Y13007/AJ295761), K. brevifolia var. leiolepis (JX644894/JX644699/ JX644808), K. bulbosa (-/Y12979/AY040601), Kyllingiella microcephala (-/AY040592/AJ295807), K. polyphylla (-/Y13013/-), Lipocarpha microcephala (JX644895/JX644700/JX644797), L. nana (-/AM999847/AJ295762), Oxycaryum cubense (-/AM999850/-), Queenslandiella hyalina (-/AM999854/-), Remirea maritima (-/AM999855/AY040604), Scirpoides holoschoemus (-/AM999871/AY344176), S. thunbergii (-/ AJ404727/AJ295812), Sphaerocyperus erinaceus (-/AM999876/AJ295764), Volkiella disticha (-/EF178561/-). 